IdeAs

Idées d'Amériques

$14 \mid 2019$

Populismes dans les Amériques

\title{
Populismos en las Américas
}

Luc Capdevila, François Vergniolle de Chantal y Jean-Christian Vinel

Traductor. Marta Gómez

CpenEdition

Journals

Edición electrónica

URL: http://journals.openedition.org/ideas/6612

DOI: $10.4000 /$ ideas.6612

ISSN: 1950-5701

Editor

Institut des Amériques

Referencia electrónica

Luc Capdevila, François Vergniolle de Chantal y Jean-Christian Vinel, «Populismos en las Américas », IdeAs [En línea], 14 | 2019, Publicado el 01 octubre 2019, consultado el 23 septiembre 2020. URL http://journals.openedition.org/ideas/6612 ; DOI : https://doi.org/10.4000/ideas.6612

Este documento fue generado automáticamente el 23 septiembre 2020

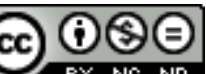

IdeAs - Idées d'Amériques est mis à disposition selon les termes de la licence Creative Commons Attribution - Pas d'Utilisation Commerciale - Pas de Modification 4.0 International. 


\title{
Populismos en las Américas
}

\author{
Luc Capdevila, François Vergniolle de Chantal y Jean-Christian Vinel \\ Tradución : Marta Gómez
}

1 En los diez últimos años, el populismo se ha afianzado como una noción, a menudo, clave para analizar la evolución política y social de un gran número de países europeos y americanos. Su uso sigue siendo sin embargo bastante negativo, ya que en la mayoría de los casos se refiere a una interpelación directa al pueblo basada en el resentimiento contra las élites y/o ciertos grupos sociales y en la defensa de un arsenal de medidas «simples» y demagógicas. De hecho, se utiliza principalmente para denunciar al adversario y son muy pocos los responsables políticos -a excepción de Jean-Luc Mélenchon, de La France insoumise, Hugo Chávez o los líderes de Podemos en España (Chazel L. 2019) - que reivindican este sello con orgullo ${ }^{1}$. En otras palabras, el populismo es percibido ante todo como una forma degradada de vida democrática. En este sentido lo analiza Pierre Rosanvallon (2011), quien ve en él una triple simplificación: primero, una simplificación política, al enfrentar a un pueblo fantaseado y homogéneo con élites corruptas; segundo, una simplificación institucional, al rechazar cualquier contrapeso frente a la voluntad popular; y, por último, una simplificación social, que atribuye al pueblo una identidad clara y definida ${ }^{2}$.

2 No obstante, el populismo es también un concepto con prácticas y estilos muy diferentes. En las Américas ha sido invocado en los últimos tiempos para designar a corrientes y sensibilidades políticas muy diversas y referirse a movimientos como Occupy Wall Street o el Tea Party, a dirigentes como Bernie Sanders y Donald Trump, e incluso a gobiernos. En el Sur se ha utilizado tanto para referirse a los regímenes llamados «nacional-populares» de América Latina - la Venezuela chavista, la Bolivia de Evo Morales o la Argentina bajo los gobiernos de los Kirchner- como para designar a corrientes ultraconservadoras, como la que encarna Jair Bolsonaro, actual presidente de Brasil, o a los gobiernos neoliberales de los años 90 (Fujimori en Perú, Collor de Mello en Brasil, Bucaram en Ecuador, etc.). Dichos gobiernos, pese a estar dirigidos por «hombres fuertes» elegidos en contextos de crisis política, recuperaron prácticas de interpelación al pueblo, de contacto inmediato con la sociedad según nuevos procedimientos (catódicos, por ejemplo, en los años 90 y digitales en la actualidad), de 
enérgica encarnación del poder, siendo a veces directos herederos de viejas organizaciones populistas (Menem en Argentina). Sin embargo, al abandonar las políticas redistributivas y de intervención económica propias de los «viejos populismos de América Latina», participaron en los llamados «neopopulismos» definidos a partir de «la fusión de populismo y neoliberalismo» (Freidenberg F., 2007).

En estas condiciones, son muchos los que vacían de contenido el concepto: dado que no se trata en sí de una ideología, el populismo se reduce a sus múltiples usos. Su ubicuidad enmascara de hecho una cierta confusión conceptual (Mudde C. 2007, Hermet G., 2001, Taguieff P-A., 1997, Laclau E., 2008), tanto más cuanto que el populismo parece ser la sombra de la democracia (Arditi, B. 2004, Canovan M., 1999). Si bien el populismo actual refleja la sensación de que las democracias se tambalean bajo el peso de demandas económicas, sociales, identitarias y de seguridad, que con frecuencia adoptan un discurso de denuncia de las élites y de defensa de un pueblo virtuoso, su esencia sigue siendo imprecisa. Por una parte, porque en el debate se mezclan dos niveles de discurso: el de los propios actores y el de los analistas, sean estos politólogos o científicos sociales. Y por otra parte, porque el carácter transnacional y la diversidad del fenómeno tienden a enmascarar las diferencias entre los casos nacionales. La historia del populismo en Europa es de hecho muy diferente a la de Estados Unidos, Canadá o América Latina. En el Viejo Continente, el populismo se refiere por lo general a movimientos de extrema derecha (Mudde, C. 2007) o, como decía George Lavau (1970), a la «función tribunicia» de los partidos de izquierda. En cambio, en Estados Unidos, cuna del Populist Party, el populismo designa un tipo de lenguaje político que refleja una pasión igualitaria que surgió de la Revolución americana (Kazin M., 1995). En América Latina, considerada a menudo como su «tierra por excelencia» (Hermet G., 2001), lo que la convierte en el «paradigma del populismo moderno» (Dorna A., 1999), el concepto se refiere sobre todo al «populismo de gobierno» más que de «denuncia» o de «oposición» (Rosanvallon P., 2011), cuya diversidad de experiencias ha marcado profundamente el siglo xx en el subcontinente (Marques Pereira B., Garibay D., 2011) y cuya herencia sigue siendo sólida en las primeras décadas del tercer milenio. Con todo, la «frecuencia» y la «imprecisión» del concepto nos obligan a afinar el contexto de su uso, lo que conduce a determinar una pluralidad de movimientos y regímenes históricamente localizados, sobre todo porque, salvo algunas excepciones, «nadie se dice o pretende ser populista» (Rouquié A., [1987] 1998).

En Estados Unidos, el populismo tiene profundas raíces que se remontan a la fundación del país. Desde un punto de vista teórico, la correlación entre el primer país, cuya constitución de 1787 estipula «We The People... Do», y el populismo, que reivindica los principios básicos de la democracia (regla de la mayoría y soberanía popular), confirma hasta qué punto el populismo sigue a la democracia como su propia sombra (Arditi, B., 2004). La relación entre ambos está, sin embargo, llena de tensiones, como demuestra ampliamente la historia de Estados Unidos. Ya en los años 1780, los padres fundadores federalistas denunciaron la "tiranía de la mayoría», una expresión que coincide plenamente con el uso contemporáneo del término «populismo». Es por ello por lo que la constitución ideada por James Madison y los otros delegados de Filadelfia multiplicó los checks and balances para contrarrestar a esta tiranía tan temida. Desde entonces, muchos movimientos populistas - tanto de derechas como de izquierdas- han criticado esos «contrapesos» institucionales como medios de acallar la voz del pueblo. Como escriben Yves Mény e Yves Surel (2002), los movimientos populistas comparten la idea de que la democracia solo significa el poder del pueblo. Con ello explotan de forma 
voluntaria la brecha entre los ideales democráticos -que adivinamos por ejemplo en el famoso discurso de Lincoln de 1863 en el que alabó «el gobierno del pueblo, por el pueblo y para el pueblo»-y el funcionamiento elitista de la democracia representativa, tal y como la analizan una serie de politólogos y teóricos «realistas», desde Joseph Schumpeter hasta Robert Dahl, Giovanni Sartori, sin olvidar a Bernard Manin. Esta crítica es lancinante en la vida política estadounidense y se repite a intervalos regulares pero con una característica singular que es que estos movimientos populistas no critican nunca la constitución. Pueden pedir su reforma (como en el caso de la izquierda) o su respeto (caso de la derecha), pero nunca su abolición.

5 La particularidad de Estados Unidos reside también en el hecho de que el populismo en este país se ha asociado históricamente con movimientos progresistas, a diferencia de las democracias europeas, donde la gran mayoría de los populismos son de derechas. De hecho, fue un periodista de Kansas quien en 1890 utilizó por primera vez el término «populismo» para referirse al People's Party, un tercer partido que acabó convirtiéndose en una importante fuerza política en la elección presidencial de 1892 con más del $8 \%$ de los sufragios. La aparición de este movimiento de protesta en la América rural, en un momento de transición entre un capitalismo de propietarios individuales y un capitalismo dominado por las grandes empresas, ha alimentado un amplio debate historiográfico. Basándose en la Escuela de Frankfurt, Richard Hofstadter presentaba el populismo como una reacción irracional y patológica contra la modernización económica. En su opinión, el populismo ilustraba el «estilo paranoico» de la vida política estadounidense cuyo libertarismo de derechas, encarnado por Goldwater, demostraba el potencial (Hofstadter R., 1955, 1964). No obstante, esta tesis fue cuestionada por historiadores que, en la línea de Lawrence Goodwyn, subrayaban la impregnación democrática de un movimiento que tenía una fuerte dimensión asociativa y cuya influencia legislativa también fue visible en las primeras leyes que regían el trabajo en las fábricas, así como en algunas leyes del New Deal (Goodwyn L., 1978, Postels C., 2007, Sanders E., 1999). Ciertamente, en la década de 1930 el populismo adquirió tintes amenazantes e incluso fascistas con Huey Long y el Padre Coughlin pero, como muestra Alan Brinkley, conservaba una dimensión democrática y llevó a Roosevelt y a los artífices del New Deal a adoptar reformas sociales importantes (Brinkley A., 1982).

De hecho, la gran dificultad para analizar el populismo en Estados Unidos radica en su enorme complejidad durante el siglo xx. Para Michael Kazin, hay que hacer una distinción entre el People's Party y el lenguaje populista (en el sentido que le da al término el historiador Gareth Stedman Jones) que legó a la vida política estadounidense. Dicho lenguaje, que enfrenta a un pueblo virtuoso y trabajador, representante de la esencia estadounidense, con una élite de parásitos que la amenaza, funciona, según Kazin, como el sustituto de una retórica de clase asumida, aunque los demócratas y la izquierda estadounidense no son sus únicos representantes: a partir de la década de 1950, el populismo se convierte en un mecanismo esencial de la reconfiguración de la derecha estadounidense, quien lo utilizó para criticar a las élites intelectuales progresistas y a sus proyectos de ingeniería social, atrayendo así a una parte del electorado obrero. En un contexto de crecientes tensiones ligadas a la lucha contra la discriminación racial y sexual en el trabajo, a las guerras culturales y a la crisis económica de los años 70, el populismo sirve a la defensa de una América blanca y conservadora. De George Wallace a Ronald Reagan y Pat Buchanan, este populismo de derechas ensalza la América trabajadora y critica en ocasiones a los lobbies de K Street, 
aunque su contenido ideológico y su relación con las clases sociales sigue siendo ambigua dado que conduce a reformas que reflejan los intereses de las élites económicas y que contribuyen de esa forma al auge del neoliberalismo (Kazin M., 1995, 2017, Frank T., 2004).

7 En suma, el arraigo del populismo en Estados Unidos ilustra la ausencia de cualquier tradición marxista de peso -que se hizo todavía más marginal tras la Revolución bolchevique y luego, la Guerra Fría- y el descrédito consecuente de los argumentos de clase. Sin embargo, su maleabilidad y su afianzamiento en la derecha desde hace casi sesenta años sin duda reflejan también la necesidad de definir sus vínculos con la historia social y política de la América periurbana y el antiestatismo de las clases medias que en este país forman la base electoral del Partido Republicano (McGirr L., 2001).

Por estas razones, incluir a Donald Trump en la trama del populismo estadounidense no es tarea fácil, lo que probablemente explica por qué muchos observadores prefieren recuperar la tesis de Hofstadter, que ha recobrado una cierta vigencia. Muchos fueron los que desacreditaron a Trump como una anomalía de la vida política estadounidense afirmando que solo logró conquistar el Partido Republicano y luego la presidencia gracias a un cúmulo de circunstancias. Sin embargo, el fenómeno Trump es mucho más complejo de lo que sus discursos dejan entrever, sobre todo porque su electorado, a pesar de los cambios a nivel local en el Rust Belt, encaja con el electorado tradicional del Partido Republicano, pero también porque sus posiciones contra la inmigración y en favor del proteccionismo remiten a la política desarrollada por el Partido Republicano a finales del siglo xix. Tras años de movilización conservadora decididamente populista, Trump puede representar efectivamente una especie de agotamiento de esta «revolución conservadora» de las últimas décadas, pero sobre todo constituye un ejemplo perfecto de lo que P-A Taguieff define como una «actitud populista» (1997, p. 15), independiente de visiones o tradiciones más o menos estructuradas, políticamente indeterminada pero idealizadora de lo "popular». Más aún, la administración Trump representa una etapa crucial en la historia del populismo estadounidense en el sentido de que ya no es solo un movimiento extra institucional sino que, bien al contrario, está instalado en el centro del poder.

En América Latina, en cambio, la experiencia con gobiernos populistas es mucho más importante. El contexto de la aparición del término «populismo» allí está ligado al desarrollo de las ciencias sociales en el subcontinente a finales de los años $50 \mathrm{y}$ principios de los 60. En aquel periodo, sociólogos y politólogos se apropiaron del concepto para analizar los regímenes autoritarios y nacionalistas que dieron origen a las políticas de regulación y redistribución características de la secuencia que acababa de terminar (Quattrocchi-Woisson D., 1997). Aplicado primero al peronismo en Argentina (Germani G., 1962; di Tella T., 1964) y al getulismo en Brasil (Cardoso F., Weffort F. (eds.), 1970), el concepto se extendió rápidamente por todo el subcontinente para abarcar el periodo entre los años 1920-1960 en el cual algunos partidos (el APRA en Perú, el Partido Revolucionario Febrerista en Paraguay o el MNR en Bolivia), líderes sin un acceso previo al poder (César Sandino en Nicaragua, Jorge Eliécer Gaitán en Colombia) y gobiernos (el México posrevolucionario, Gualberto Villarroel en Bolivia, Velasco Ibarra en Ecuador) encarnaron las respuestas a la crisis institucional (ficción democrática) y económica (modelo agroexportador) de las repúblicas oligárquicas. El denominador común fue poner al «pueblo» en el centro de sus discursos de 
movilización, ya se tratara de los «descamisados» de Perón en Argentina, de los «olvidados» del Ecuador de Velasco Ibarra, de los «pobres» en el Brasil dirigido por Getulio Vargas, o de los «pies descalzos» (pynandi) colorados en Paraguay.

Más allá de la diversidad de experiencias nacionales vividas, existen varios elementos que permiten caracterizar la singularidad e historicidad de los populismos latinoamericanos. En general, los líderes fueron impulsados por una dinámica democrática asociada a la extensión del sufragio y promovieron políticas desarrollistas basadas en la regulación estatal y la redistribución social. Los discursos de movilización se basaron en una doble polarización: el pueblo contra las élites, la nación contra el imperialismo. Eran efectivamente regímenes de movilización ligados a los movimientos sociales, basados en un fuerte liderazgo sindical y/o partidista. Por último, la mayor parte de estos regímenes emprendieron una transformación limitada de las estructuras socioeconómicas y, en este sentido, la nacionalización de sectores estratégicos tuvo solo en contadas ocasiones a la reforma agraria como corolario. En consecuencia, lograron un frágil equilibrio al organizar un «Estado de compromiso» que debía preservar la propiedad de las élites, al tiempo que respondía, en parte, a las expectativas sociales de los sectores populares y de las clases medias.

11 Estos regímenes de «transición» que trataban de «incluir a los sectores populares en el orden político» (Rouquié A., 1998) marcaron una etapa fundamental en la construcción del proceso democrático en América Latina. Las convocatorias electorales y la ampliación del sufragio trajeron la llegada al poder de Perón en Argentina en 1946 y 1952 y Estenssoro en Bolivia en 1952, y el regreso en 1951 de Vargas en Brasil. En general, estos gobiernos «populistas» latinoamericanos iniciaron y promovieron las políticas indigenistas de las primeras décadas del siglo veinte con vistas a forjar la nación y materializar una identidad nacional enraizada en el territorio y basada en la autoctonía, pero también con miras a integrar a todos los sectores populares, ya fuesen indígenas, afrolatinoamericanos (Andrews G. R., 2007) o incluso descendientes de inmigrantes. Los conflictos de los años 60 pusieron de manifiesto los límites ideológicos de los populismos históricos latinoamericanos. La vía revolucionaria en Cuba y el deseo de cambio social, cuyo principio rector era la reforma agraria, rompieron el equilibrio alcanzado con el Estado de compromiso y fracturaron los movimientos cuya unidad a veces se basaba únicamente en la expresión de lealtad al líder, mientras que las dictaduras de Guerra Fría de los años 70 afirmaron su deseo de poner fin a la «aberración populista» (Quattrocchi Woisson D., 1997).

En cuanto a los gobiernos reformistas de los años 2000-2010, calificados también como «populistas» por sus detractores (Panizza F., 2008), solo hasta cierto punto pueden ser considerados como herederos de los regímenes del siglo pasado. La correlación con los «viejos populismos» es aún más problemática al tratarse de «neopopulismos» contemporáneos que articulan la interpelación al pueblo y la implementación de políticas neoliberales y de apoyo a las grandes empresas. Con todo, los primeros fueron ante todo fruto de la consolidación democrática que puso fin a las dictaduras de Guerra Fría y de la alternancia que se impuso tras la crisis social provocada por dos décadas de políticas de ajuste estructural y desregulación neoliberal. Más allá de las políticas redistributivas y de una acción real contra la pobreza iniciada en los años 2000 por los gobiernos de izquierdas, algunos líderes han retornado efectivamente a un poder personalista y divisor y a prácticas de contacto inmediato con «el pueblo», articulando al mismo tiempo la acción gubernamental con las organizaciones de base, ya sean 
asociativas, comunitarias, sindicales o comunales. Estos últimos elementos pueden caracterizar a estos nuevos "populismos» latinoamericanos pero, a diferencia de sus predecesores policlasistas y «nacional-populares», estos han funcionado en un contexto democrático consolidado y se han posicionado claramente a la izquierda en el tablero político nacional e internacional.

En definitiva, ¿existe un modelo populista? ¿Un modelo americano? ¿O podríamos más bien hablar de un laboratorio americano con experiencias populistas diversas y numerosas singularidades nacionales que plantean aspectos como los vínculos entre populismo y construcción democrática, entre populismo y electoralismo o entre populismo y participación?

Este número de IdeAs ofrece un enfoque original sobre la cuestión mostrando, a partir de estudios de caso locales, cómo los historiadores, sociólogos y politólogos que trabajan sobre América del Sur y del Norte emplean la noción de populismo para explicar racionalmente fenómenos sociales, políticos y económicos. En una democracia, ¿qué es lo que diferencia al populismo del llamamiento al voto de los electores, sobre todo de las clases populares? Como escriben Yves Mény e Yves Surel (2002), los movimientos populistas se expresan y se comportan como si la democracia pudiera reducirse solo al poder del pueblo. Sin embargo, este diagnóstico general necesita ser afinado porque, lejos de estar en radical oposición frente a la sofisticación de la democracia liberal y representativa (Manin, B., 2005), los populismos pertenecen a un mismo contínuum. A veces, el populismo adopta formas que resultan tóxicas para la democracia pero, bajo otras formas, el populismo también puede operar lo que James Morone (1990) llama el «deseo democrático» (Democratic Wish). Por ello, como explica Joseph Lowndes en su capítulo del Oxford Handbook of Populism (2017), «sin duda es mejor analizar el populismo por lo que hace que por lo que es» (it is perhaps better then to analyze not what populism is but what populism does). En este sentido, el objetivo de este número es contribuir a identificar los criterios que permitan definir el populismo a partir de experiencias y análisis inspirados en el continente americano, desde Canadá al Cono Sur.

\section{BIBLIOGRAFÍA}

Andrews, George Reid, Afro-Latinoamérica, 1800-2000, Madrid/Frankfurt am Main, Iberoamericana/Vervuert, 2007.

Arditi, Benjamin, "Populism as a Spectre of democracy", Political Studies, vol.52, n¹, mars 2004, p.135-143.

Brinkley, Alan, Voices of Protest: Huey Long, Father Coughlin and the Great Depresssion, New York: Knopf, 1982.

Canovan, Margaret, “Two Strategies for the Study of Populism”, Political Studies, vol.30, $\mathrm{n}^{\circ} 4$, 1982. 
Cardoso, Fernando Enrique y Weffort, Francisco, (Eds.), América latina. Ensayos de interpretación sociológico-política, Santiago de Chile, Editorial Universitaria, 1970.

Chazel, Laura, «De l'Amérique latine à Madrid : Podemos et la construction d'un «populisme de gauche», Revue Pôle Sud, n50, 2019, p. 121-138.

Di Tella, Torcuato, El sistema político argentino y la clase obrera, Buenos Aires, Eudeba, 1964.

Dorna, Alexandre, Le populisme, Paris PUF, 1999.

Frank, Thomas, What's the Matter With Kansas? New York, Holt, 2004.

Freidenberg, Flavia, La tentación populista. Una vía al poder en América latina, Madrid, Editorial Sintésis, 2007.

Germani, Gino, Política y sociedad en una época de transición. De la sociedad tradicional a la sociedad de masas, Buenos Aires, Paidós, 1962.

Goodwyn, Lawrence, Democratic Promise: The Populist Moment in America, New York, Oxford UP, 1976.

Hermet, Guy, Les populismes dans le monde, Paris, Fayard, 2001.

Hofstadter, Richard, The Age of Reform: From Bryan to FDR, New York, Knopf, 1955.

Hofstadter Richard, The Paranoid Style in American Politics, New York, Vintage, 1964.

Kaltwasser, Cristóbal Rovira \& al. (eds.). The Oxford Handbook of Populism, Oxford: Oxford University Press, 2017

Kazin, Michael, The Populist Persuasion, Ithaca, Cornell UP, 1995. Nouvelle édition en 2017.

Laclau, Ernesto, La raison populiste, Paris, Seuil, 2008.

Lowndes, Joseph, «Populism in the United States», p.232-246, in Cristobal R. Kaltwasser, et al., The Oxford Handbook of Populism, Oxford, Oxford University Press, 2017.

McGirr, Lisa, Suburban Warriors, The Origins of the New American Right, Princeton, Princeton UP, 2001.

Marques-Pereira, Bérengère, Garibay, David, La politique en Amérique latine. Histoires, institutions et citoyennetés, Paris, Armand Colin, 2011.

Manin, Bernard, The Principles of Representative Government, Cambridge, Mass., Cambridge University Press, 2005

Morone, James, The Democratic Wish. Popular Participation and the Limits of American Government, New York, Basic Books, 1990.

Mudde, Cas, Populist Radical Right Parties in Europe, Cambridge,UK, Cambridge UP, 2007.

Panizza, Francisco, «Fisuras entre Populismo y Democracia en América Latina», Stockholm Review of Latin American Studies, n 3, 2008, p. 81-93.

Postels, Charles, The Populist Vision, New York, Oxford, 2007.

Quattrocchi-Woisson, Diana, «Les populismes latino-américains à l'épreuve des modèles d'interprétation européens», Vingtième siècle, revue d'histoire, n56, 1997, p. 161-183.

Rosanvallon, Pierre, «Penser le populisme», laviedesidees.fr, 2011.

Rouquié, Alain, Amérique latine. Introduction à l'extrême-Occident, Paris, Seuil, 1998 [1987 1ère édition] 
Sanders, Eilzabeth, Roots of Reform, Farmers, Workers, and theAmerican State, 1877-1917, Chicago, The University of Chicago Press, 1999.

Surel,Yves, Mény, Yves, 'Populism: The Pathology of Democracy?', in Democracies and the Populist Challenge, London: Palgrave, 2002, 3-6.

Taguieff, Pierre-André, «Le populisme et la science politique: du mirage conceptuel aux vrais problèmes», Vingtième Siècle, $n^{\circ} 56$, octobre-décembre 1997, p.4-33.

Wiles, Peter, «A Syndrome, Not a Doctrine: Some Elementary Theses on Populism», in Ghita Ionescu, Ernest Gellner, ed., Populism. Its Meaning and National Characteristics, London, Weidenfeld and Nicolson, 196

\section{NOTAS}

1. «Mélenchon, le populisme assumé», radio France Inter, L'édito politique, 29 de agosto de 2017: https://www.franceinter.fr/emissions/l-edito-politique/l-edito-politique-29-aout-2017.

2. Pierre Rosanvallon, «Penser le populisme», 27 de septiembre de 2011: http:// www.laviedesidees.fr/Penser-le-populisme.html.

\section{AUTORES}

\section{LUC CAPDEVILA}

(Universidad de Rennes 2 - ARENES)

\section{FRANÇOIS VERGNIOLLE DE CHANTAL}

(Universidad de París - LARCA, UMR 8225)

JEAN-CHRISTIAN VINEL

(Universidad de París - LARCA, UMR8225) 